\title{
molecules
}

ISSN 1420-3049

www.mdpi.com/journal/molecules

Review

\section{Absorption-Enhancing Effects of Bile Salts}

\section{Eskandar Moghimipour ${ }^{1}$, Abdulghani Ameri ${ }^{2}$ and Somayeh Handali ${ }^{1, *}$}

1 Nanotechnology Research Center, Ahvaz Jundishapur University of Medical Sciences, Ahvaz 61357-33184, Iran; E-Mail: moghimipour_e@ajums.ac.ir

2 Department of Drug and Food Control, Faculty of Pharmacy, Ahvaz Jundishapur University of Medical Sciences, Ahvaz 61357-33184, Iran; E-Mail: ghaniameri@yahoo.com

* Author to whom correspondence should be addressed; E-Mail: handali_s81@yahoo.com; Tel.: +98-9161-147998; Fax: +98-6113-738381.

Academic Editor: Derek J. McPhee

Received: 19 June 2015/ Accepted: 31 July 2015 / Published: 10 August 2015

\begin{abstract}
Bile salts are ionic amphiphilic compounds with a steroid skeleton. Among the most important physiological properties of bile salts are lipid transport by solubilization and transport of some drugs through hydrophobic barriers. Bile salts have been extensively studied to enhance transepithelial permeability for different marker molecules and drugs. They readily agglomerate at concentrations above their critical micelle concentration (CMC). The mechanism of absorption enhancement by bile salts appears to be complex. The aim of the present article was to review bile salt structure and their application as absorption enhancers and the probable mechanism for increasing permeation based on previous studies.
\end{abstract}

Keywords: bile salts; drug delivery; absorption enhancers

\section{Introduction}

Bile salts are amphipathic steroidal bio-surfactants that are derived from cholesterol in the liver [1-3]. The synthesis of bile salts is the major route for elimination of cholesterol from the body [4]. Bile salts are endogenous surfactants which have been employed widely as absorption enhancers to increase drug transport across various biological barriers such as the blood brain barrier, skin, mucosa, cornea, buccal, nasal, pulmonary and intestinal membranes $[5,6]$. They act as absorption enhancers by increasing the 
solubility of hydrophobic drugs or by increasing the fluidly of the apical and basolateral membranes [7] and promote the chemical and enzymatic stability of drugs [8].

\section{Structure and Synthesis}

Bile acids are ionic amphiphilic compounds with a steroid skeleton. As shown in Figure 1, the structure of bile acids consists of four rings, three six carbon rings (A, B and C) and one five carbon ring (D). With regards to this structure, several bile acids are shown in Table $1[9,10]$. The concave $(\alpha)$ side of the steroid skeleton of bile acid molecules is hydrophilic due to the presence of $\mathrm{OH}$ groups, while the convex $(\beta)$ side with its angular methyl groups is hydrophobic [11]. This structure makes them very different from traditional surfactants, which are often composed of a polar head group and a long non-polar tail [9].

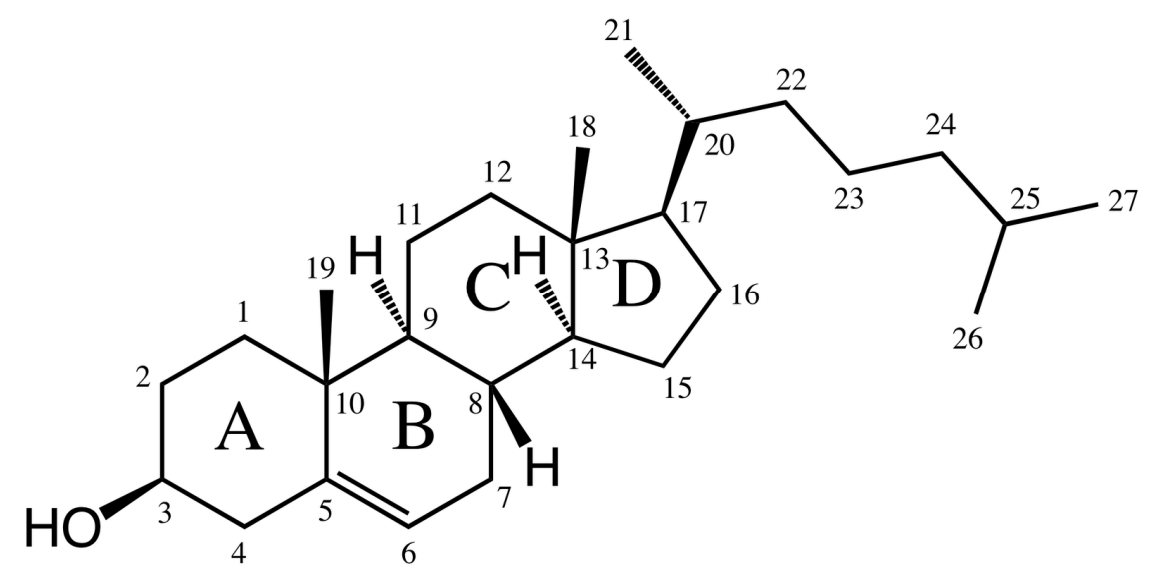

Figure 1. Common chemical structure of bile acids.

Bile salts are synthesized from cholesterol in the liver [1]. Processes of bile acids biosynthesis from cholesterol are shown in Scheme 1. Cholesterol is eliminated by hepatic biotransformation to bile alcohols or bile acids. These compounds are further biotransformed in the liver by sulfation or amidation and the produced bile salts, are secreted into bile [12]. Bile acids include two groups, primary (cholic acid and chenodeoxycholic acid) and secondary bile acids (deoxycholic acid and lithocholic acid) [9,13]. Primary bile acids are synthesized from cholesterol in the liver via different pathways including the classic and alternative ones [14]. The classical pathway (also known as the neutral pathway) is responsible for the large quantities of the bile acids synthesized by the liver $[15,16]$ and only about $10 \%$ of bile acids are produced via the alternative pathway [17]. The enzyme $7 \alpha$-hydroxylase, a cytochrome P450 enzyme which converts cholesterol to $7 \alpha$-hydroxycholesterol, is the main enzyme in the classic pathway. $7 \alpha$-Hydroxycholesterol is converted to chenodeoxycholic acid or to cholic acid by a pathway that is catalyzed by $12 \alpha$-hydroxylase [14]. The reaction catalyzed by $7 \alpha$-hydroxylase is the rate limiting step in bile acid synthesis [18]. The alternative or acidic pathway which generates chenodeoxycholic acid, involves hydroxylation of cholesterol at the 27 position by the mitochondrial enzyme sterol 27-hydroxylase. The acidic pathway can account for $25 \%$ and $9 \%$ of total bile acid synthesis in mice and humans, respectively [14]. Prior to secretion, bile acids are conjugated with taurine or glycine [14]. Conjugation of bile acids to glycine and taurine reduces the hydrophobicity of bile acids [19,20]. In human bile, the concentration of glycine conjugates (75\%) is much higher than taurine (25\%) [18]. The 
primary bile acids are converted to the secondary bile acids following intestinal bacterial hydrolysis of the amide backbone of conjugated bile acids [9]. The conjugated bile acids form further complexes with sodium to become bile salts. Several steps of the pathways biosynthesis of bile acids from cholesterol are shown Figure 2. In humans, the concentration of bile salts in gallbladder can reach to $14 \mathrm{mM} \mathrm{[21].}$ The concentrations of bile salts in different body compartments are shown in Table 2 [22]. Bile salts are categorized into three groups according to their conjugation with amino acids and their degree of hydroxylation, including trihydroxy conjugates (such as taurocholate and glycocholate), dihydroxy conjugates (such as glycodeoxycholate, glycochenodeoxycholate, taurochenodeoxycholate and taurodeoxycholate) and unconjugated forms (such as cholate, deoxycholate, and chenodeoxycholate) [23]. Approximately $60 \%$ of the bile salts in human bile are dihydroxy [24]. The dihydroxy and trihydroxy bile salts enable the solubilization of insoluble lipids including phospholipids, monoglycerides and long chain alkyl alcohols [25].

Table 1. Various types of bile acids [9].

\begin{tabular}{|c|c|c|c|c|c|c|}
\hline Bile Acid & Abbreviation & $\mathrm{R} 1(\mathrm{C}-3)$ & R2(C-6) & R3(C-7) & $\mathrm{R} 4(\mathrm{C}-12)$ & R5(C-24) \\
\hline Glycocholate & GC & $\mathrm{OH}(\alpha)$ & $\mathrm{H}$ & $\mathrm{OH}(\alpha)$ & $\mathrm{OH}(\alpha)$ & $\mathrm{NHCH}_{2} \mathrm{COO}^{-}$ \\
\hline Taurocholate & $\mathrm{TC}$ & $\mathrm{OH}(\alpha)$ & $\mathrm{H}$ & $\mathrm{OH}(\alpha)$ & $\mathrm{OH}(\alpha)$ & $\mathrm{NHCH}_{2} \mathrm{CH}_{2} \mathrm{SO}_{3}^{-}$ \\
\hline Glycolithocholate & GLC & $\mathrm{OH}(\alpha)$ & $\mathrm{H}$ & $\mathrm{H}$ & $\mathrm{H}$ & $\mathrm{NHCH}_{2} \mathrm{COO}^{-}$ \\
\hline Glycohyocholate & GHC & $\mathrm{OH}(\alpha)$ & $\mathrm{OH}(\alpha)$ & $\mathrm{OH}(\alpha)$ & $\mathrm{H}$ & $\mathrm{NHCH}_{2} \mathrm{COO}^{-}$ \\
\hline Tauroursodeoxycholate & TUDC & $\mathrm{OH}(\alpha)$ & $\mathrm{H}$ & $\mathrm{OH}(\beta)$ & $\mathrm{H}$ & $\mathrm{NHCH}_{2} \mathrm{CH}_{2} \mathrm{SO}_{3}^{-}$ \\
\hline Taurohyodeoxycholate & THDC & $\mathrm{OH}(\alpha)$ & $\mathrm{OH}(\alpha)$ & $\mathrm{H}$ & $\mathrm{H}$ & $\mathrm{NHCH}_{2} \mathrm{CH}_{2} \mathrm{SO}_{3}^{-}$ \\
\hline Glycohyodeoxycholate & GHDC & $\mathrm{OH}(\alpha)$ & $\mathrm{OH}(\alpha)$ & $\mathrm{H}$ & $\mathrm{H}$ & $\mathrm{NHCH}_{2} \mathrm{COO}^{-}$ \\
\hline Glycochenodeoxycholate & GCDC & $\mathrm{OH}(\alpha)$ & $\mathrm{H}$ & $\mathrm{OH}(\alpha)$ & $\mathrm{H}$ & $\mathrm{NHCH}_{2} \mathrm{COO}^{-}$ \\
\hline Glyco-7-oxo-lithocholate & G-7-oxo-LC & $\mathrm{OH}(\alpha)$ & $\mathrm{H}$ & $=\mathrm{O}$ & $\mathrm{OH}(\alpha)$ & $\mathrm{NHCH}_{2} \mathrm{COO}^{-}$ \\
\hline Taurodeoxycholate & TDC & $\mathrm{OH}(\alpha)$ & $\mathrm{H}$ & $\mathrm{H}$ & $\mathrm{OH}(\alpha)$ & $\mathrm{NHCH}_{2} \mathrm{CH}_{2} \mathrm{SO}_{3}^{-}$ \\
\hline Taurochenodeoxycholate & TCDC & $\mathrm{OH}(\alpha)$ & $\mathrm{H}$ & $\mathrm{OH}(\alpha)$ & $\mathrm{H}$ & $\mathrm{NHCH}_{2} \mathrm{CH}_{2} \mathrm{SO}_{3}^{-}$ \\
\hline Glycodeoxychoate & GDC & $\mathrm{OH}(\alpha)$ & $\mathrm{H}$ & $\mathrm{H}$ & $\mathrm{OH}(\alpha)$ & $\mathrm{NHCH}_{2} \mathrm{COO}^{-}$ \\
\hline Glycoursodeoxycholate & GUDC & $\mathrm{OH}(\alpha)$ & $\mathrm{H}$ & $\mathrm{OH}(\beta)$ & $\mathrm{H}$ & $\mathrm{NHCH}_{2} \mathrm{COO}^{-}$ \\
\hline Taurolithocholate & TLC & $\mathrm{OH}(\alpha)$ & $\mathrm{H}$ & $\mathrm{H}$ & $\mathrm{H}$ & $\mathrm{NHCH}_{2} \mathrm{CH}_{2} \mathrm{SO}_{3}^{-}$ \\
\hline Taurohyocholate & THC & $\mathrm{OH}(\alpha)$ & $\mathrm{OH}(\alpha)$ & $\mathrm{OH}(\alpha)$ & $\mathrm{H}$ & $\mathrm{NHCH}_{2} \mathrm{CH}_{2} \mathrm{SO}_{3}^{-}$ \\
\hline $\begin{array}{c}\text { Glycol-3 } \alpha-6 \text {-keto- } 5 \beta- \\
\text { cholate }\end{array}$ & $\begin{array}{c}\text { Glycol3 } \alpha 6 \text { keto- } \\
5 \beta \text {-cholate }\end{array}$ & $\mathrm{OH}(\alpha)$ & $=\mathrm{O}$ & $\mathrm{H}$ & $\mathrm{OH}(\alpha)$ & $\mathrm{NHCH}_{2} \mathrm{COO}^{-}$ \\
\hline Tauro- $\alpha$-hyocholate & $\mathrm{T}-\alpha-\mathrm{MC}$ & $\mathrm{OH}(\alpha)$ & $\mathrm{OH}(\alpha)$ & $\mathrm{OH}(\alpha)$ & $\mathrm{H}$ & $\mathrm{NHCH}_{2} \mathrm{CH}_{2} \mathrm{SO}_{3}^{-}$ \\
\hline Tauro- $\beta$-hyocholate & $\mathrm{T}-\beta-\mathrm{MC}$ & $\mathrm{OH}(\alpha)$ & $\mathrm{OH}(\alpha)$ & $\mathrm{OH}(\beta)$ & $\mathrm{H}$ & $\mathrm{NHCH}_{2} \mathrm{CH}_{2} \mathrm{SO}_{3}^{-}$ \\
\hline
\end{tabular}

$\alpha$, indicates a steric orientation below the steroid ring plane and $\beta$ above.

Table 2. The concentrations of bile salts in human body [22].

\begin{tabular}{cc}
\hline Compartment & Concentration \\
\hline Gall bladder & $10-50 \mathrm{mmol} / \mathrm{L}$ \\
Gut & $\sim 4-20 \mathrm{mmol} / \mathrm{L}$ \\
Liver Canaliculi & $\sim 5 \mathrm{mmol} / \mathrm{L}$ \\
Portal vein blood & $0.1 \mathrm{mmol} / \mathrm{L}$ \\
Peripheral blood & $5-20 \mu \mathrm{mol} / \mathrm{L}$ \\
\hline
\end{tabular}




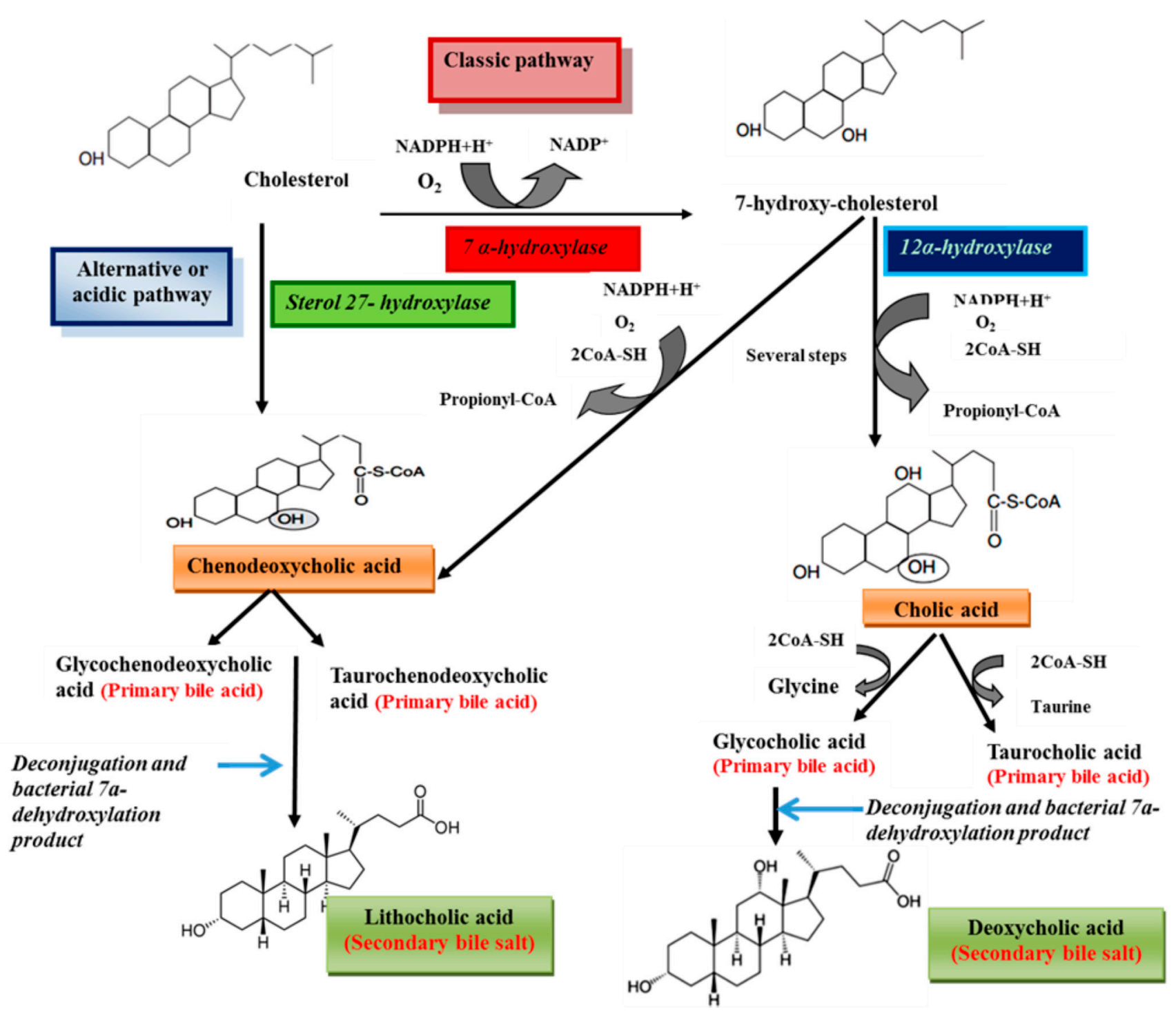

Scheme1. Schematic representation of bile acids biosynthesis from cholesterol.

Bile acids perform a negative feedback regulation on their synthesis. The binding of excess bile acids by the nuclear receptor farnesoid X receptor (FXR) induces the expression of small heterodimer partner (SHP), transcriptional repressor. Then SHP interact with other transcription factors, liver receptor homolog-1 (LRH-1) and hepatocyte nuclear factor- $4 \alpha(\mathrm{HNF}-4 \alpha)$, that bind to the bile acid response elements (BAREs) located within the promoter region of the $7 \alpha$-hydroxylase and $12 \alpha$-hydroxylase genes, which results in repression of bile acid synthesis [16,26].

\section{Physiological Functions}

The main biological function of bile salts is to solubilize dietary lipids and liposoluble vitamins in the gut, transport lipids, enhance proteolytic cleavage of dietary proteins and accelerate their absorption [4,27-29]. Bile acids induce biliary lipid secretion and due to their physico-chemical properties can form mixed micelles with phospholipids which assist in cholesterol solubilization in the gallbladder, as a result, prevent formation of cholesterol gallstones [16,30]. While some studies demonstrated that the micelles formed by bile salts play a role in the early crystallization that leads to gall stone formation in human [28], it is known that long term treatment of human gallstone patients with 
chenodeoxycholic acid (CDCA) decreases hepatic very-low-density lipoprotein (VLDL) production and plasma triglyceride levels [31]. Results showed that conjugated bile salts have superior emulsification properties compared to unconjugated bile salts and can better facilitate the absorption of lipophilic compounds [9]. About $95 \%$ of bile acids are reabsorbed in the ileum and transported to the liver to inhibit $7 \alpha$-hydroxylase and bile acid synthesis. $7 \alpha$-hydroxylase deficiency leads to hypercholesterolemia and atherosclerosis in humans [31]. Also, they possess potent antimicrobial activity in the intestine [4] especially, against Gram-positive bacteria. The antimicrobial activity of bile salts may be related to oxidative DNA damage [32], disrupting cell membranes and cellular homeostasis [33]. It was observed that cirrhotic patients, who secrete significantly lower amounts of bile salts than healthy people, contain higher levels of bacteria in the intestine. The patients often affected by systemic infections [32]. They can modulate secretion of lipoproteins from hepatocytes [15] and at low concentrations, stimulate proliferation of the colonic epithelium and are involved in the regulation of colonic mucosal growth [34]. Bile acids can influence on immune cells in the mucosa [35] and stimulate intestinal immunity [36]. As signaling molecules, bile acids are able to modulate glucose, lipid and energy metabolism [30]. They stimulate activation of $G$ protein coupled receptor (TGR5) in the enteroendocrine cells that promote glucagon like peptide-1 (GLP-1) release. GLP-1 is important mediator of insulin release from pancreatic $\beta$ cells [37]. It was observed that bile acids are able to induce activation of nicotinamide adenine dinucleotide phosphate oxidase in hepatocytes, and the following increase reactive oxygen species (ROS) production that is essential for bile acid induced apoptosis [29]. In addition, bile acids facilitate intestinal calcium absorption [16].

Bile salts are secreted into the duodenum and adsorb onto the surface of lipid to further emulsify them and to prepare this interface for the enzymatic break down by the pancreatic lipases. Lipases can hydrolyses the lipids that composed of triglycerides, into free fatty acids, monoglycerides and diglycerides. Some of these compounds are soluble, therefore they can be removed from the surface of lipid and become incorporated within micelles of bile salts in order to be absorbed by the intestinal mucosa [38]. Bile salts are capable to inhibit the precipitation of furosemide drug solutions owing to its pH-dependent solubility [39]. Studies showed that bile acids play key homeostatic roles in glucose metabolism, xenobiotic detoxification of toxins, cholesterol and lipid metabolism. Moreover, they can employ for the treatment of illnesses such as tamoxifen-resistant breast cancer, prostate cancer, colon cancer, Alzheimer's disease, atherosclerosis, obesity and metabolic disorders [40].

\section{Physico-Chemical Properties}

Because of several physiological functions of bile salts, their micellar properties have been extensively studied. In aqueous solutions, bile salts aggregate and form micelles in concentrations above critical micelle concentration (CMC) [11]. By forming micelles, bile salts can facilitate transcellular passage and enhance absorption [41]. CMC values of some bile salts are mentioned in Table 3. CMC values are determined by surface tension and dye solubilization methods [12]. Surface tension is measured by an improved maximum bubble pressure method. This technique measures the pressure in a bubble formed at the end of an immersed capillary into which flows a constant stream of air. The bubble reaches its maximum pressure when its diameter is equal to that of the capillary, which occurs just before the bubble escapes. The maximum pressure is proportional to the surface tension. The surface tension 
depends on the monomer activity in solution. By increasing concentrations, aggregation begins to form and the surface tension versus log concentration graph shows a significant reduction in slope in the CMC region [12]. Dye solubilization method is performed using Orange OT (1-O-tolyl azo-2-naphthol), which is a water-insoluble and micelle-soluble dye. Solubilization of Orange OT takes place only when micelles are present, and the solubilized amount is directly proportional to the concentration of micelles [42]. Also, the fluorescence probe technique is used for determination of CMC. This method involves the use of hydrophobic fluorescence dyes (such as pyrene and pyrene-3-carboxaldehyde) which are sensitive to the polarity of the solubilizing medium and will exhibit different fluorescence behavior in micellar and nonmicellar solutions. Such changes of behavior as a function of surfactant concentration have been used to determine the CMC. Ananthapadmanabhan et al. in 1985 showed that the CMC values estimated from the fluorescence characteristics of pyrene-3-carboxaldehyde was consistently closer to CMC values of surfactants that determined using surface tension [43].

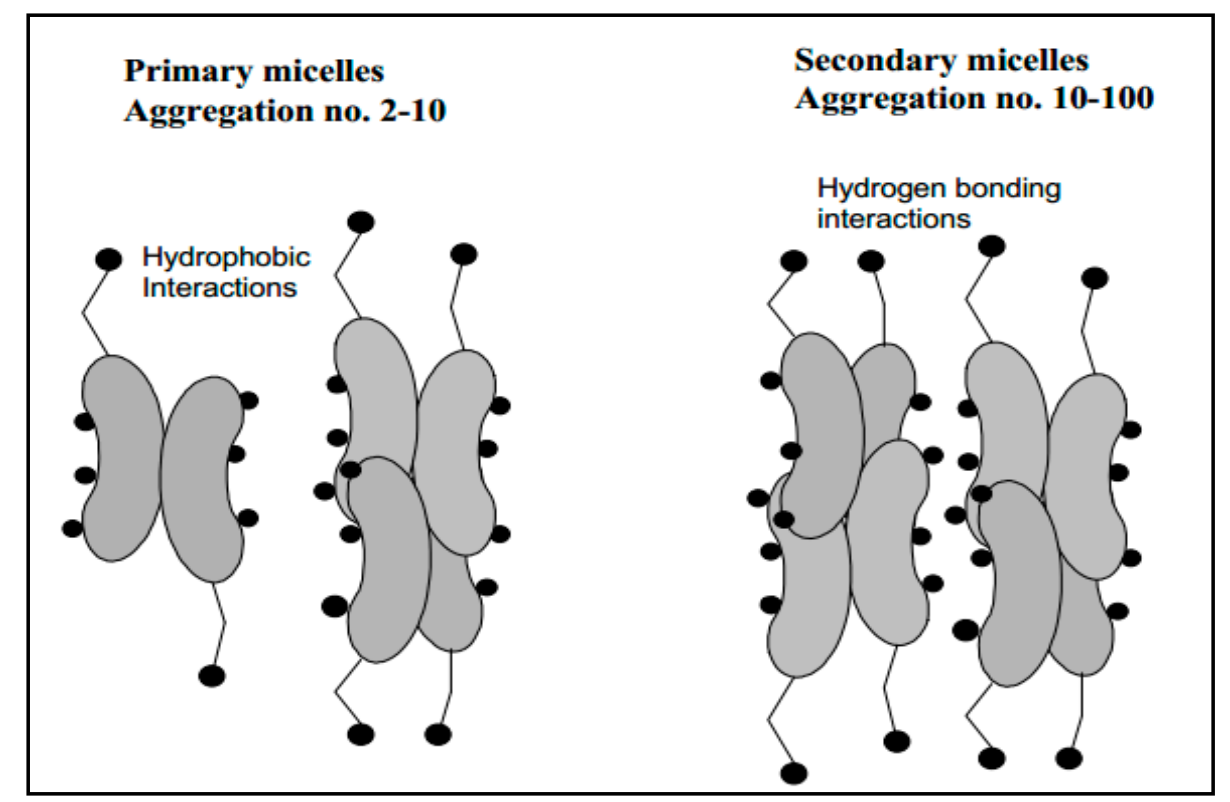

Figure 2. Primary and secondary aggregation model of bile salt micelles [18].

Bile salts can form either primary or secondary micelles. Primary bile salt micelles have aggregation numbers from 2 to 10 and are formed via hydrophobic interactions, while secondary micelles (aggregation numbers 10-100) are formed via hydrogen bonding interactions of the primary micellar structures (Figure 2) $[18,44]$. The $\mathrm{pH}$, at which $\mathrm{CMC}$ formation occurs, is called the critical micellar $\mathrm{pH}(\mathrm{CMpH})[13]$ at which the solubility increases markedly [45]. CMC of dihydroxy bile salts are usually below CMC of trihydroxy bile salts. The high CMC of trihydroxy bile salts is ascribed to their higher solubility in water [18]. It has been reported that conjugation with glycine or taurine slightly lowers CMC of trihydroxy bile salts [46]. The orientation of hydroxy substituents also influences the CMC values and changing of a hydroxy substituent from $\alpha$-to $\beta$-configuration increases the CMC values. Moreover, addition of $\mathrm{Na}^{+}$ ion to a total concentration of $0.15 \mathrm{M}$ lowers $\mathrm{CMC}$ [12]. 
Table 3. CMC value of some bile salts.

\begin{tabular}{ccc}
\hline Bile Salt & CMC (mM) & Ref. \\
\hline $\mathrm{NaTC}$ & 8 & {$[47]$} \\
$\mathrm{NaC}$ & 4 & {$[48]$} \\
$\mathrm{NaLC}$ & 1 & {$[45]$} \\
$\mathrm{NaGC}$ & $2-5$ & {$[48]$} \\
$\mathrm{NaTCDC}$ & $2.5-3$ & {$[49]$} \\
\hline
\end{tabular}

GDC: Glycodeoxychoate; NaTC: sodium taurocholate; NaC: sodium cholate; NaLC: sodium lithocholate; NaGC: sodium glycocholate; NaTCDC, sodium taurochenodeoxycholate.

\section{Bile Salts as Absorption Enhancer}

Because of biocompatibility, bile salts have been widely used as permeation enhancers. They can enhance drug penetration through various biological membranes by interacting with phospholipids in cell membranes. Therefore, they have been employed as permeation enhancers in topical dosage forms including buccal, ocular, nasal, and transdermal routes of administration [39,50].

\subsection{Oral Drug Delivery}

Drug administration through the oral route is the most preferred route by patients and has many advantages including, children's acceptabilty, ease of administration, lack of pain and discomfort associated with injections [51,52]. Song et al. investigated enhancement of intestinal absorption of salmon calcitonin (sCT) from proliposomes containing bile salts [53]. Oral bioavailability of $\mathrm{sCT}$ is very low due to enzymatic degradation in gastrointestinal tractand poor permeation across intestinal epithelial cells. One approach for overcoming this problem is the use of absorption enhancers. Song et al. applied different permeation enhancers to improve intestinal absorption of $\mathrm{sCT}$. According to Figure 3, in comparison with different absorption enhancers, sodium taurodeoxycholate (NaTDC) (drug:NaTDC; 0.75:2.5) showed the largest Merit index value. The Merit index was calculated as the ratio of the fold increase in permeability of sCT over the fold decrease in transepithelial electrical resistance (TEER) value in Caco-2 cell monolayers for each compound. It has been previously reported that some of bile salts including NaTDC, are known to form lipophilic ion-pair complexes with various organic cations, which increasethe permeability of the cations across biological membranes. Since sCT is a hydrophilic and cationic molecule, it was demonstrated that the effect of NaTDC in enhancing permeability of sCT might be due to ion-pair forming ability of the bile salts with $\mathrm{SCT}$ [53].The findings of Song et al., is contrary to the results of Cetin et al [54], that reported no significant difference was found between nanoparticle formulations with and without NaTDC on oral absorption of SCT (drug:NaTDC; 1:1) [54]. This difference might be due to the used ratio of drug:NaTDC, which were quality different. 


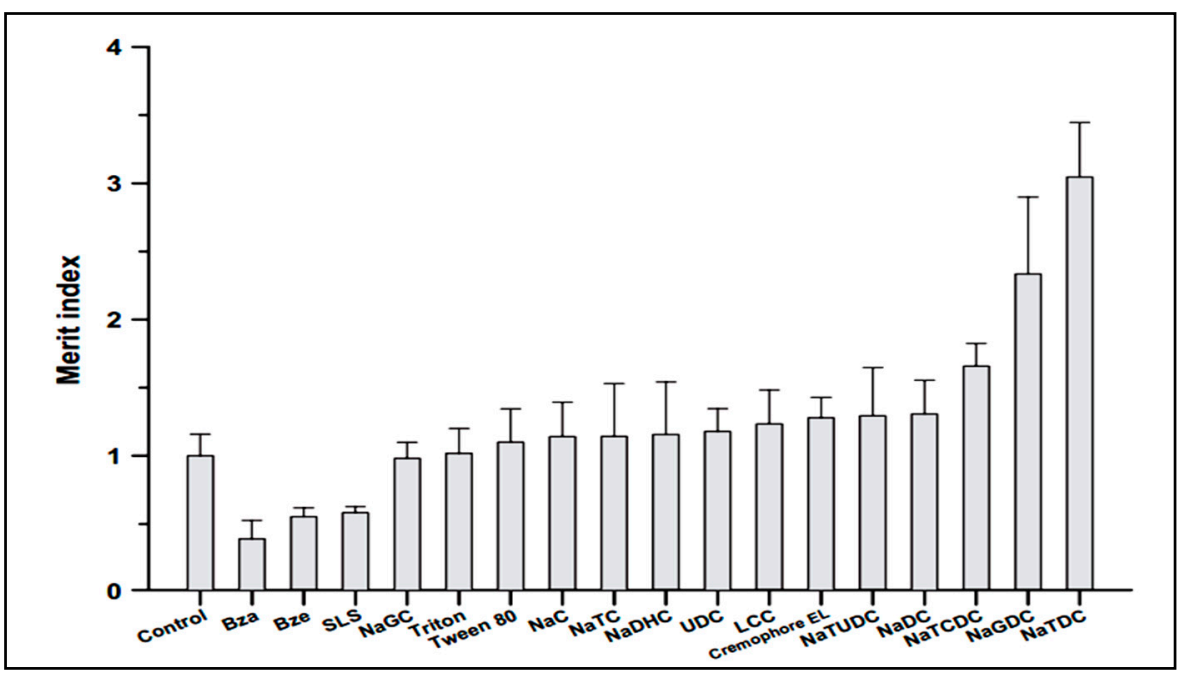

Figure 3. Effect of various surfactants on the Merit index of sCT.SLS: sodium lauryl sulfate, Bza: benzalkonium chloride, Bze: benzetonium chloride, NaGC: sodium glycocholate, $\mathrm{NaC}$ : sodium cholate, NaTC: sodium taurocholate, NaDHC: sodium dehydrocholate, UDC: ursodeoxycholate, LCC: lauroylcarnitine chloride, NaTUDC: sodium tauroursodeoxycholate, NaDC: sodium deoxycholate, NaTCDC: sodium taurochenodeoxycholate, NaGDC: sodium glycodeoxycholate, NaTDC: sodium taurodeoxycholate [53].

It has been previously shown that sodium glycocholate (NaGC) could improve insulin absorption more than sodium salicylate as absorption enhancer through oral delivery [55]. It was observed that the effect of $\mathrm{NaGC}$ on intestinal absorption of insulin is site dependent and the duodenum appeared to be the optimal site for insulin oral delivery [56].

\subsection{Transdermal Delivery}

The major obstacle for drug transportation through skin is the outer layer of skin, the stratum corneum. It is the actual physical barrier to most substances contacting skin [57-59]. Many approaches have been employed in order to increase absorption of drugs through skin. Among them is utilization of absorption enhancers such as bile salts. Sodium deoxycholate $(\mathrm{NaDOC})$ is one of the bile salts that forms stable gels and can be useful as drug carrier for topical skin application [60]. Senyigit et al. in 2011, observed that in vitro flux of betamethasone-17-valerate from NaDOC gels across rat skin was $2.5(0.05 \%)$ and 8.5 times $(0.1 \%)$ higher than commercial cream $(0.1 \%)$, respectively. Furthermore, in vivo anti-inflammatory activity was in agreement with in vitro drug permeation. Histology studies indicated that NaDOC gel has no irritant effect on the skin [61]. It has been also shown that sodium tauroglycocholate (NaTGC) is a potent absorption enhancer for drug delivery to the skin. Kouchak et al. in 2014 found that NaTGC $(100 \mu \mathrm{g} / \mathrm{mL})$ improved the flux of aminophylline through snake skin compared to simple gel $(p<0.05)$ [62]. Moreover, in previous studies, it was reported that NaTGC could increase absorption of theophylline through shed snake skin [63]. It has been suggested that NaTGC, as a surfactant, enhances the penetration of compounds into stratum corneum followed by interaction with keratin filaments that leads to corneocyte disruption or may modify peptide or protein in the lipid bilayer stratum corneum that increase permeability [64]. 


\subsection{Nasal Delivery}

Nasal drug delivery is a suitable route for low dose drugs which show poor stability in the gastrointestinal tract. Drugs administered intranasally avoid liver first-pass metabolism and the route is non-invasive, making ease of administration by the patient in long term therapy a favorable aspect of nasal delivery $[65,66]$. The most important factor limiting the nasal absorption of polar drugs is low membrane permeability [67]. To overcome this problem, different approaches have been attempted, including the use of absorption enhancers such as bile salts [68,69]. As shown in Table 4, many researchers have investigated bile salts as absorption enhancers for nasal delivery of insulin. Hirai et al. in 1981 demonstrated that bile salts may promote insulin transport across nasal mucosa by retarding insulin degradation by leucine aminopeptidase, a proteolytic enzyme. These compounds were found to be less irritating to the nasal mucosa, have lower hemolytic activity and less protein release than other surfactants [70]. In addition, it has been reported that bile salts may affect the nasal membrane by creating temporal pores and enhance the permeability of it, or form reverse micelles within nasal membranes, which insulin monomers can diffuse through polar channels from the nares into the blood stream [71]. It has been shown that bile salts cause nasal irritation when used above a concentration of $0.3 \%$ [72]. Sodium glycodeoxycholate ( $\mathrm{NaGDC}$ ) is more effective as an absorption promoter in the nasal mucosa than sodium glycocholate (NaGC). Because of the lack of a hydroxyl group at the 7 position of the steroids, NaGDC is more lipophilic than NaGC [73]. Nevertheless, NaGC has been widely used as an enhancer in nasal absorption due to its relatively low toxicity compared to other bile salts. It is believed that $\mathrm{NaGC}$ is able to transport large and hydrophilic molecules by interaction with membrane lipids, enzymatic inhibition and opening of tight junctions between epithelial cells [74].

Table 4. Bile salts as absorption enhancers for nasal delivery of insulin.

\begin{tabular}{|c|c|c|c|}
\hline Bile Salts & Animals & Result & Ref. \\
\hline Sodium deoxycholate & Rat & Blood glucose levels dropped to $60 \%$ of initial levels after $30 \mathrm{~min}$ & {$[75]$} \\
\hline Sodium glycocholate & Rat & Increases insulin efficacy & {$[76]$} \\
\hline Sodium taurocholate & Rabbit & $\begin{array}{c}\text { Microcrystalline cellulose suspension containing insulin and } \\
\text { sodium taurocholate }(1 \% \mathrm{w} / \mathrm{w}) \text { sprayed into the nasal cavity } \\
\text { provided a bioavailability of } 8.36 \%\end{array}$ & {$[77]$} \\
\hline Sodium glycocholate & Dog & Increases absorption of insulin & {$[78]$} \\
\hline Sodium cholate & Rabbit & Reduces blood glucose $(60.06 \%)$ & [79] \\
\hline
\end{tabular}

\subsection{Buccaland Mucosal Drug Delivery}

Buccal drug delivery has high patient acceptability due to the elimination of pain associated with injections. It is fully vascularized and more accessible for the administration and removal of a dosage form. Nausea and vomiting induced through oral administration is avoided. Furthermore, drugs, which show poor bioavailability via oral route, can be administered conveniently through buccal route. But, buccal mucosa is less permeable and so unable to give a rapid absorption window. Penetration enhancers are capable of decreasing penetration barrier of buccal mucosa [80]. Bile salts have been extensively investigated for their ability to enhance buccal penetration of tracer molecules and drugs [81]. SDGC is widely used to improve the transbuccal delivery of drugs [82]. Hoogstraate et al. in 1996 
showed that enhancement effect of SGDC on buccal permeation is concentration dependent. They observed that SDGC at concentration of $10 \mathrm{mM}$ enhanced the flux of fluorescein isothiocyanate (FITC)-dextran through paracellular routes, while, at high concentrations (100 mM) enhanced drug delivery through paracellular and transcellular routes [83]. Sodium cholate is present in the RapidMist ${ }^{\mathrm{TM}}$ spray that is used for delivery of insulin to the buccal mucosa [84]. Regarding the differential scanning calorimetry (DSC) results of Gandhi et al., 1992, it was demonstrated that the influence of sodium deoxycholate on transbuccal delivery of salicylic acid may be related to the effect of penetration enhancer on the protein domain that involve the uncoiling and extending of the protein helix, and thereby opening the polar pathway [85]. It has been found that unconjugated bile salts that are less hydrophobic, are more effective than their conjugated forms in absorption of calcitonin through buccal rat mucosa in vivo [86]. Oral administration of decitabine (an anticancer drug) is not ideal because of its degradation under the acidic conditions in the stomach. Also, due to poor chemical stability of decitabine, intravenous infusion is not appropriate. In 2007 Mahalingam et al., evaluated the feasibility of transbuccal delivery of decitabine and the effect of $\mathrm{NaTC}, \mathrm{NaGC}$, sodium deoxytaurocholate (NaDTC) and sodium deoxyglycocholate (NaDGC) on its permeability. The permeation enhancement of dihydroxy bile salts (NaDTC and NaDGC) across the buccal mucosa was better than that of trihydroxy bile salts (NaTC and $\mathrm{NaGC}$ ). Furthermore, it was observed a 38-fold enhancement in flux was achieved with $10 \mathrm{mM}$ of NaDGC. These researchers were believed that the enhancements in the flux of decitabine in the presence of bile salts may occur by a complex process including solubilization and micellar entrapment of intercellular lipids, denaturation and extraction of proteins, enzyme inactivation and tissue swelling [50].

\subsection{Rectal Drug Delivery}

Yamamoto et al. in 1992 investigated the effect of $\mathrm{NaGC}, \mathrm{NaTC}$ and sodium deoxycholate (NaDC) on the improvement of rectal penetration of insulin in the albino rabbit. They found that NaGC was more effective than NaTC but less effective than NaDC in improving the rectal absorption of insulin in rabbits [87]. Docetaxel (DCT) is one of the most anti-cancer drugs in treatment of head and neck cancer, breast cancer, gastric cancer and ovarian cancer. Due to low aqueous solubility and poor oral bioavailability, DCT has greatly limited therapeutic applications. Therefore, Kim et al. in 2014 designed nanomicelles as delivery systems composed of DCT/poloxamer 407 (P407)/poloxamer 188 (P188) Tween $80 / \mathrm{NaTC}$ for improvement of the bioavailability and anti-tumor efficacy of DCT upon rectal administration (Figure 4). Poloxamer, was selected for the formulation of unique thermosensitive and bioadhesive DCT-loaded nanomicelles. Because its reverse gelation property, polaxamer remains in liquid state at room temperature $\left(\sim 25^{\circ} \mathrm{C}\right)$, while gelifying at physiological body temperature $\left(\sim 37^{\circ} \mathrm{C}\right)$. Also, Tween 80 acts as an additional solubilizing agent, and can form a eutectic mixture with DCT. As shown in Figure 5, compared to control, DCT-loaded nanomicelles significantly reduced the tumor growth of mice $(p<0.001)$. Moreover, the pharmacokinetic results showed that NaTC was influential in improving the half-life and plasma level of DCT. Although the elevated plasma level of DCT from the bile salt group did not enhance the anti-tumor potential, DCT-loaded nanomicelles could reduce the drug-related side effects, such as hypersensitivity reactions and fluid retention, while retaining the potential anti-tumor efficacy in clinical subjects [88]. 


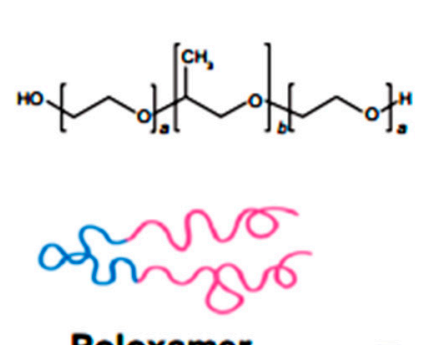

Poloxamer

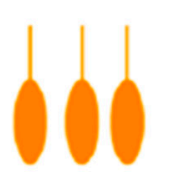

Sodium taurocholate (NaTC)

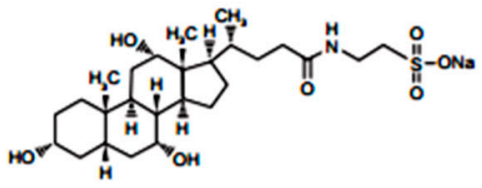

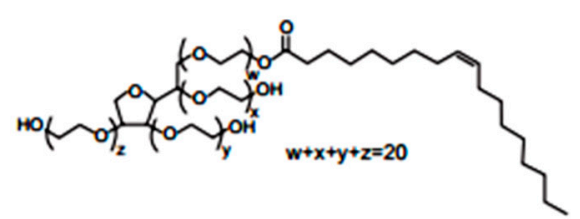

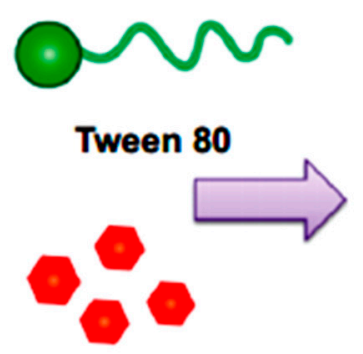

Docetaxel

(DCT)

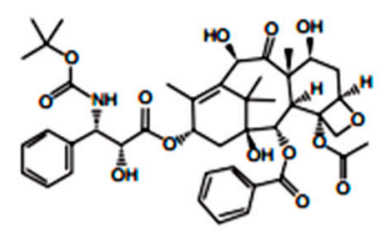

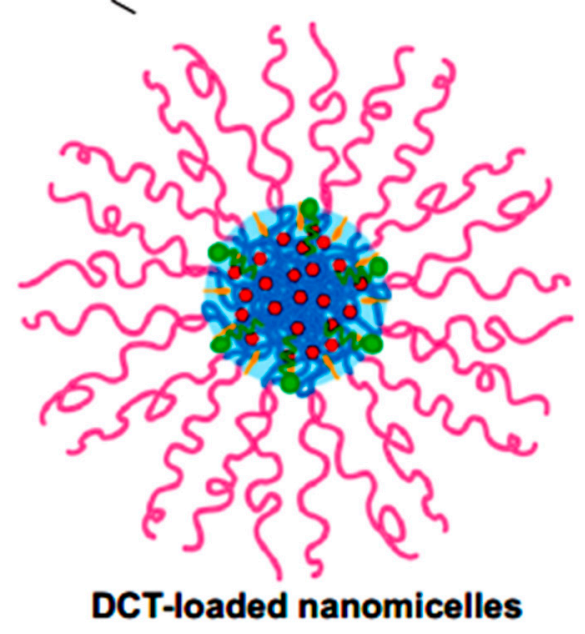

DCT-loaded nanomicelles

Figure 4. Preparation of DCT-loaded nanomicelles containing NaTC [88].

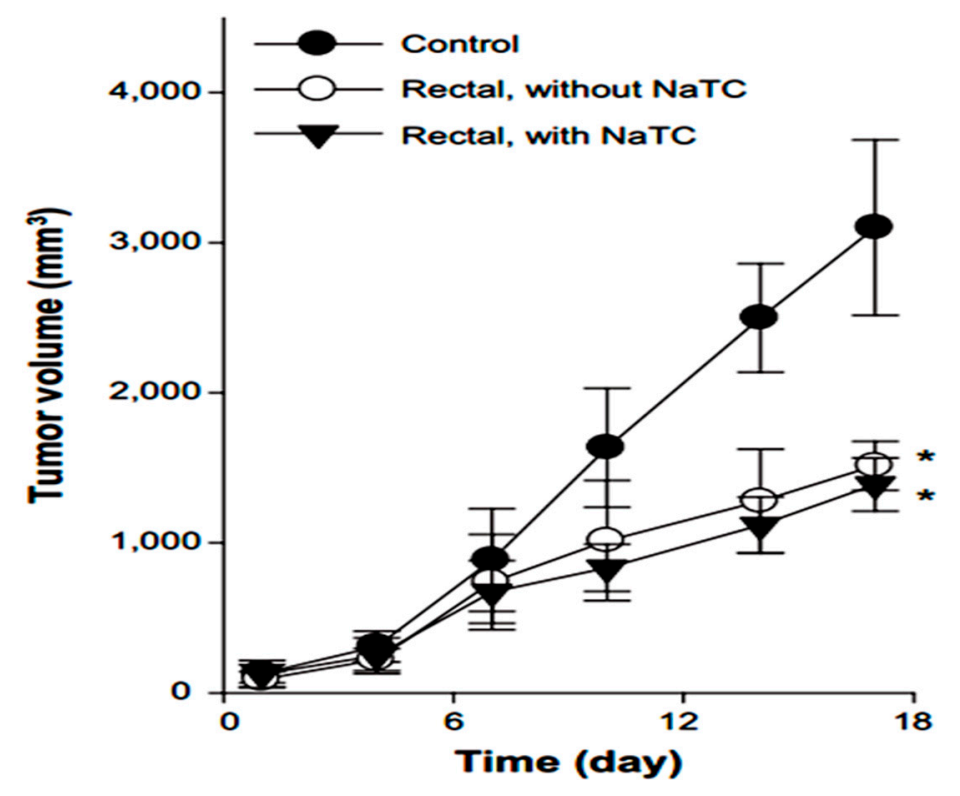

Figure 5. Anti-tumor efficacy of DCT-loaded nanomicelles with and without NaTC after rectal administration [88].* Significantly smaller than control group $(p<0.01)$.

\subsection{Ocular Drug Delivery}

Saettone et al. in 1996 evaluated bile salts as absorption enhancers for permeation of $\beta$-blocking agents (atenolol, timolol, levobunolol and betaxolol) through isolated rabbit corneas. According to their results, the permeation of atenolol was significantly increased (5.8-fold) by $0.05 \%$ TDC. Also, DC and UDC at concentrations $0.05 \%$ could enhance permeation of timolol about 5.2 and 2.1-fold, respectively [89]. Yamamoto et al. in 1989 investigated systemic insulin delivery in the albino rabbit 
with $\mathrm{NaGC}, \mathrm{NaTC}, \mathrm{NaDC}$ at a concentration of $1 \%$. The results showed bioavailability of insulin was $4.9 \%$ to $7.9 \%$ with $\mathrm{NaGC}, 3.6 \%$ to $7.8 \%$ with $\mathrm{NaTC}$ and $8.2 \%$ to $8.3 \%$ with $\mathrm{NaDC}$, as compared to $0.7 \%$ to $1.3 \%$ in the absence of absorption promoters [90].

\section{Mechanism of Action of Bile Salts as Absorption Enhancers}

The mechanism of absorption enhancement by bile salts includes extracting membrane protein or lipids, membrane fluidization, producing reverse micelles in the membrane and creation aqueous channels. It is reported that at higher concentrations of bile salts, membrane lipids may be extracted, to form micelles and enhance transcellular transport [41,80,91]. Bile salts enhance transport of hydrophilic drugs through the paracellular route by incorporation into the cell membrane where, at a certain concentration, they could form reverse micelles that included water molecules, thus creating hydrophilic pores in the cell membrane [92]. Also, the bile salts can increase the paracellular transport by disruption of the hemidesmosomes [93] or by binding to $\mathrm{Ca}^{+2}$ in the regions of tight junctions [94,95]. It is believed that filamentous actin (F-actin) play a major role in controlling of paracellular permeability. According to the results of F-actin staining studies and reduction of transepithelial electrical resistance (TEER) values in the presence of bile salts performed by Lin et al., damage to the tight junction between the epithelial cells and thus an increase in paracellular permeability was reported [96]. Moreover, bile salts can reduce the viscosity and elasticity of the mucus layer adhering to all mucosal surfaces and consequently increase epithelial membrane permeability [95,97,98]. In different studies, it has been shown that bile salts have inhibitory effects on mucosal membrane peptidases [6]. The effect is reversible and concentration dependent [99]. It was found that sodium glycocholate acts as a protease inhibitor, to reduce insulin metabolism on mucosal membranes 5-fold [100]. In addition, it was reported that the effect of bile salts on the oral mucosal absorption of human calcitonin in rats was related to the inhibition of degradation of calcitonin in mucosa [101]. It was also observed that the effect of bile salts on the transport of drugs is concentration dependent. Senel et al. in 1998 reported that enhancement of the permeation of morphine hydrochloride through buccal epithelium was dependent on the concentration of sodium glycocholate (NaGC). Drug permeation was increased in the presence of $100 \mathrm{mM} \mathrm{NaGC}$, whereas no enhancement was obtained at $10 \mathrm{mM} \mathrm{NaGC} \mathrm{[48].} \mathrm{It} \mathrm{has} \mathrm{been} \mathrm{reported} \mathrm{that} \mathrm{some} \mathrm{bile} \mathrm{salts}$ inhibit the active efflux of P-glycoprotein (Pgp) substrates, probably indirectly, by changing the lipid environment of the Pgp transporter or by interaction with Pgp. Studies showed that Pgp function was not affected by CA, DC and TC, whereas taurolithocholate (TLCA), taurochenodeoxycholate (TCDC), glycochenodeoxycholate (GCDC) and UDC inhibit Pgp mediated drug transport. This may be due to the absence of a hydroxyl group at position 12 in TLCA, TCDC, GCDC and UDC that determines the structural property of inhibiting Pgp [92]. The most commonly known transport mechanisms of bile salts are shown in Figure 6. 


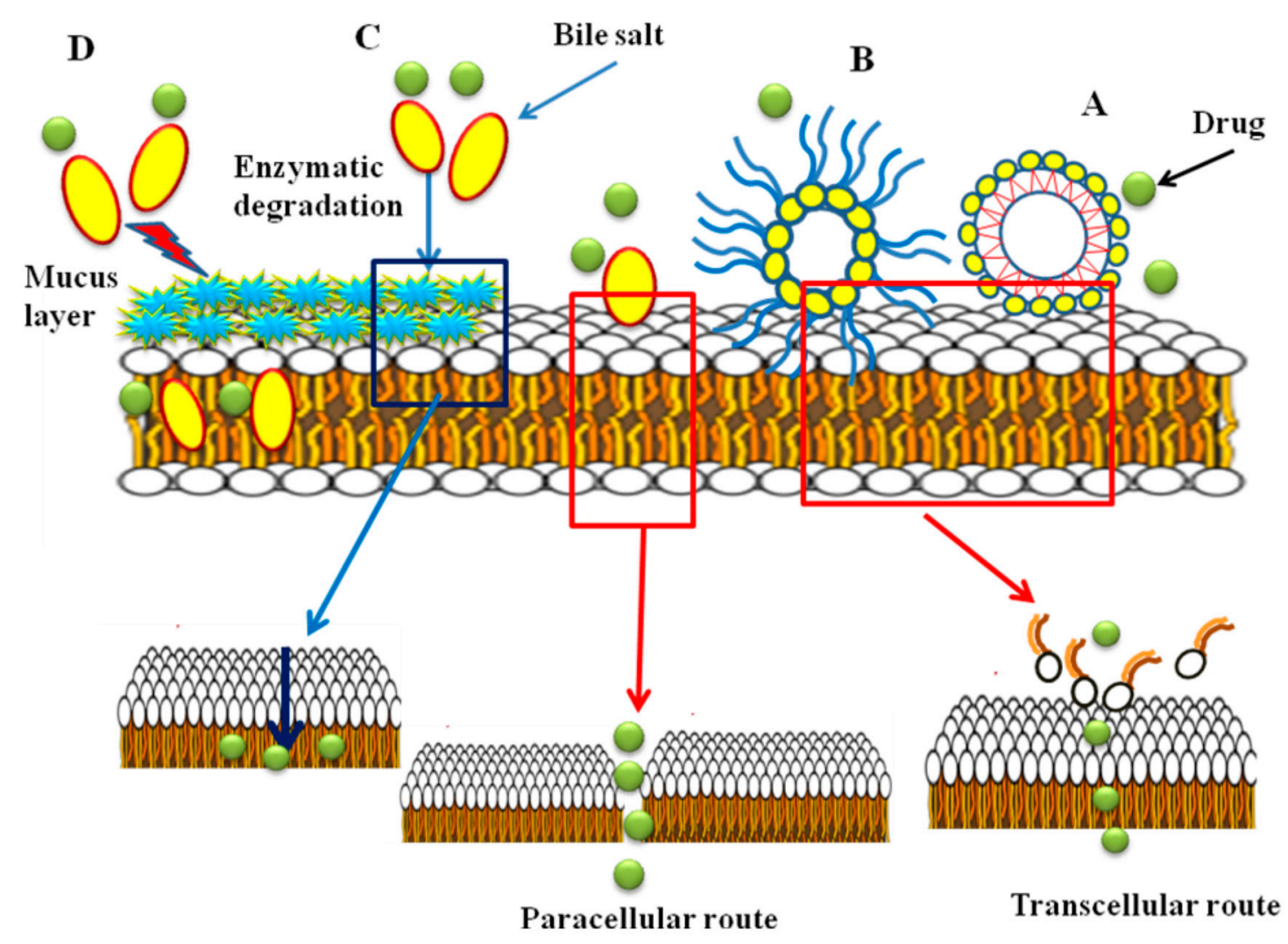

Figure 6. The most common transport mechanisms of bile salts; (A) micelle formation; (B) reverse micellization; (C) enzyme inhibition; (D) viscosity reduction of the mucus layer.

\section{Toxicity}

Bile salts have limited clinical use because of the irreversible damage to the mucosa and ciliotoxicity. It has been reported that dihydroxy bile salts are more toxic than trihydroxy bile salts. Studies showed deoxycholate is intensively ciliotoxic, with ciliary arrest occurring within $1 \mathrm{~min}$ at a concentration of $5 \mathrm{mM}$ [97]. These findings are in accord with the observation of Guus et al. in 1986, who reported that deoxycholate is extremely ciliotoxic at a concentration of $5 \mathrm{mM}$ when used for intranasal absorption of gentamicin [102], while ciliotoxicity of taurocholate is less and ciliary arrest does not occur until $30 \mathrm{~min}$, even at concentration of $30 \mathrm{mM}$ [86]. Wheatley et al. in 1988 observed that $1 \%$ deoxycholate solution caused irreversible tissue damage to sheep nasal mucosa [103]. Based on the study of Yang et al., sodium deoxycholate enhanced morphine-6-glucuronide uptake in rat brain endothelial 4 (RBE4) cells due to a cytotoxic effect. $97 \%$ cytotoxicity and $100 \%$ cytoxicity was produced at 0.5 and $1 \mathrm{mM}$ concentration, respectively [3]. Saettone et al. in 1996 found that among the bile salts (sodium deoxycholate, sodium taurodeoxycholate sodium ursodeoxycholate and sodium tauroursodeoxycholate), sodium deoxycholate at concentration of 1\% was irritant and caused corneal damage [89]. Bowe et al. reported in 1997 that sodium deoxycholate is an effective absorption enhancer for insulin. In the presence of this compound, blood glucose levels decreased to $60 \%$ of initial levels after $30 \mathrm{~min}$, but in comparison with the other absorption enhancers, it was somewhat irritant [75]. Also, high concentrations of sodium deoxycholate can damage plasma and nuclear membranes [104]. Morimoto et al. in 1998 reported that the ciliary beat activities and mucociliary transport rates were not significantly affected by sodium glycocholate at 
concentrations of 1,10 and $20 \mathrm{mM}$, whereas they were significantly reduced by 1 and $10 \mathrm{mM}$ sodium taurodeoxycholate and immediately stopped after application of $20 \mathrm{mM}$ taurodeoxycholate. Based on these results, they concluded that sodium glycocholate may be a safe and useful absorption enhancer for intratracheal drug delivery [105]. As shown in Figure 7, 0.25, 0.5 and $1 \mathrm{mM}$ sodium deoxycholate (NaDOC) and sodium taurochenodeoxycholate (NaTCDC) caused no significant change in hemolytic activity of the bile salts on the red blood cells (RBCs), while incubation at 1.5 and $2 \mathrm{mM}$ concentrations, significantly increased haemolysis $(p<0.0002)$ [106].

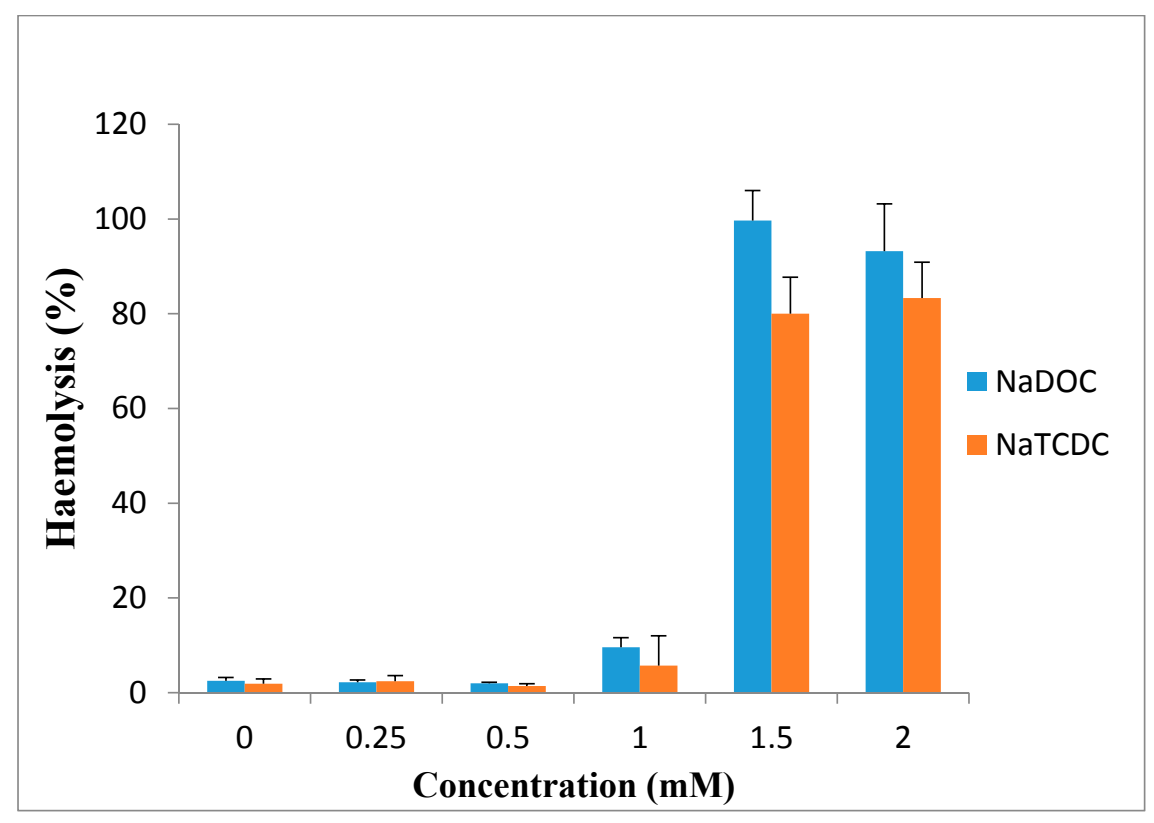

Figure 7. Percentage haemolysis of red blood cells caused by incubation with differing concentrations of NaDOC and NaTCDC (mean $\pm \mathrm{SE}, n=8$ ) (data are taken from [106]).

It has been shown that phosphatidylcholine can prevent toxicity of bile salts on gastrointestinal epithelia and membrane [21]. In 2000 Barrios et al. stated that this effect may be related to formation of less toxic mixed micelles [107]. Besides, phosphatidylcholine as an ingredient of the bile is able to bind to bile salts and form mixed micelles that can improve the dissolution of insoluble drugs [21]. Tan et al. in 2013 found that mixed micelles of $0.2 \mathrm{mM} \mathrm{NaDC}$ with $1 / 2-2 / 1$ of lecithin/ $\mathrm{NaDC}$ ratios induced significant apoptosis on Caco-2 cells compared to the control group, although, micelles with 4/1 ratio of lecithin/NaDC induced less apoptosis (Figure 8). These results indicate that more lecithin in mixed micelles causes less apoptosis [108]. Moreover, based on the findings of Zhang et al., a combination of $\beta$-cyclodextrins with $\mathrm{NaDC}$ reduces the intensity of nasal ciliotoxicity of $\mathrm{NaDC}$ [109]. It has been reported that taurine and glycine conjugates of the bile salts are somewhat less irritating to the nasal mucosa, as they are in terms of toxicity on other membranes [71]. 


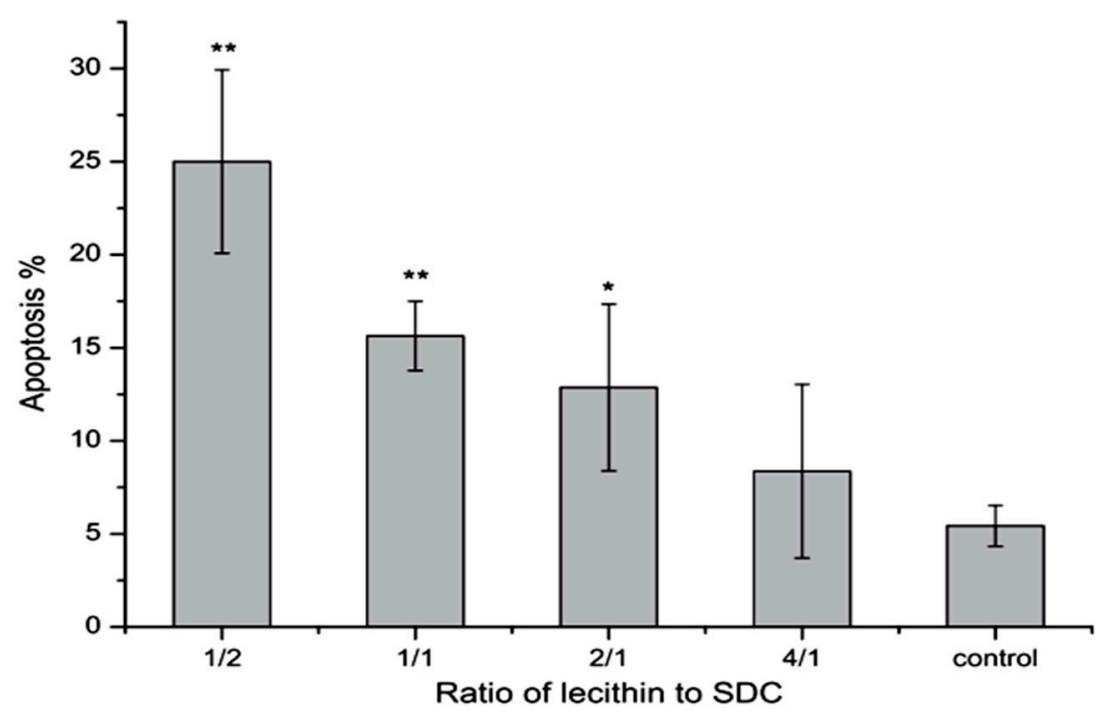

Figure 8. Effects of $0.2 \mathrm{mM}$ mixed micelles with different lecithin/ $\mathrm{NaDC}$ ratios on the apoptosis of Caco-2 cells $(n=5)$ [108]. * $p<0.05, * * p<0.01$.

\section{Novel Approaches}

Novel vesicular delivery systems containing bile salts and liposomes are known as bilosomes, act as penetration enhancers [110]. The incorporation of bile salts into liposomes can stabilize the membrane against the deleterious effects of physiological bile acids in the gastrointestinal tract [111] and facilitate internalization of the particles [112]. In addition, bilosomes are produced from natural lipids that make them biocompatible [113]. Guan et al. in 2011 encapsulated cyclosporine A in bilosomes and observed that its oral bioavailability increased due to enhanced penetration of the bilosomes [114]. Also, Conacher et al. in 2001 reported that cyclosporin A-encapsulating bilosomes can promote uptake by M-cells in Peyer's patches, and therefore increase absorption through the lymphatic system [115]. Studies showed that these carriers are suitable for oral vaccine delivery [111] and may have inherent adjuvant properties [113]. Mann et al. in 2004 found that A/Panama influenza haemagglutinin-containing bilosomes were capable of inducing systemic and mucosal immune responses by IgG and IgA antibodies, respectively [113]. In 2006 Mann et al. also showed that entrapment of tetanus toxoid in bilosomes could protect the protein against harsh environment of the stomach and its oral administration induced both systemic and mucosal immunity against bacterial protein antigen [116]. The results of a Shukla et al. study indicated that hepatitis B surface antigen-loaded bilosomes produced both systemic and mucosal antibody responses upon oral administration. Moreover, the carriers with a fivefold higher dose upon oral administration produced comparable serum antibody titres to those obtained after intramuscular immunization without, causing systemic tolerance [117].

\section{Conclusions}

Bile salt synthesis is the major route for cholesterol elimination from the body. Bile salts have been especially considered due to their efficacy in the solubilization and improving the absorption of drugs. They have been widely explored for this purpose. Bile salts increase drug absorption via paracellular 
and transcellular routes, alteration of mucus layers or enzymatic degradation. Bile salts are highly important for drug absorption and they may be considered useful aids in drug formulation.

\section{Author Contributions}

This work was carried out in collaboration between authors. Author E. Moghimipour designed the study, S. Handali prepared the first draft of the manuscript and A. Ameri edited the final manuscript. All authors read and approved the final manuscript.

\section{Conflicts of Interest}

The authors declare no conflict of interest.

\section{References}

1. NavasDiaz, A.; GarciaSa'nchez, F.; GarciaPareja, A. Cholic acid behavior in water and organic solvent: Study of normal and inverted aggregates. Colloids Surf. A 1998, 142, 27-34.

2. Gunness, P.; Flanagan, B.M.; Shelat, K.; Gilbert, R.G.; Gidley, M.J. Kinetic analysis of bile salt passage across a dialysis membrane in the presence of cereal soluble dietary fiber polymers. Food Chem. 2012, 134, 2007-2013.

3. Yang, L.; Zhang, H.; Paul Fawcett, J.; Mikov, M.; Tucker, I.G. Effect of bile salts on the transport of morphine-6-glucuronide in rat brain endothelial cells. J. Pharm. Sci. 2011, 100, 1516-1524.

4. Hagey, L.R.; Vidal, N.; Hofmann, A.F.; Krasowski, M.D. Evolutionary diversity of bile salts in reptiles and mammals, including analysis of ancient human and extinct giant ground sloth coprolites. BMC Evol. Biol. 2010, 10, 1-23.

5. Yang, L.; Tucker, I.G.; Østergaard, J. Effects of bile salts on propranolol distribution into liposomes studied by capillary electrophoresis. J. Pharm. Biomed. Anal. 2011, 56, 553-559.

6. Senel, S.; Hincal, A.A. Drug permeation enhancement via buccal route: Possibilities and limitations. J. Control. Release 2001, 72, 133-144.

7. Kesarwani, K.; Gupta, R. Bioavailability enhancers of herbal origin: An overview. Asian Pac. J. Trop. Biomed. 2013, 3, 253-266.

8. Coufalová, L.; Mrózek, L.; Rárová, L.; Placek, L.; Opatrilová, R.; Dohnal, J.; Králová, K.; Paleta, O.; Král, V.; Drašar, P.; et al. New propanoyloxy derivatives of $5 \beta$-cholan-24-oic acid as drug absorption modifiers. Steroids 2013, 78, 435-453.

9. Holm, R.; Müllertz, A.; Mu, H. Bile salts and their importance for drug absorption. Int. J. Pharm. 2013, 453, 44-55.

10. Snigdha Mishra, S.; Subuddhi, U. Spectroscopic investigation of interaction of nile blue A, a potent photosensitizer, with bile salts in aqueous medium. J. Photochem. Photobiol. B Biol. 2014, 141, 67-75.

11. Poša, M.; Sebenji, A. Determination of number-average aggregation numbers of bile salts micelles with a special emphasis on their oxo derivatives-The effect of the steroid skeleton. Biochim. Biophys. Acta 2014, 1840, 1072-1082. 
12. Roda, A.; Hofmann, A.F.; Mysels, K.J. The influence of bile salt structure on self-association in aqueous solutions. J. Biol. Chem. 1983, 258, 6362-6370.

13. Stamp, D.; Jenkins, G. An overview of bile-Acid synthesis, chemistry and function. In Bile Acids, Toxicology and Bioactivity; Royal Society of Chemistry; Jenkins, G., Hardie, L.J., Eds.; Springer: Berlin, Germany; Heidelberg, Germany, 2009; pp. 1-13.

14. AguiarVallim, T.Q.; Tarling, E.J.; Edwards, P.A. Pleiotropic roles of bile acids in metabolism. Cell Metab. 2013, 17, 657-669.

15. Torchia, E.C.; Stolz, A.; Agellon, L.B. Differential modulation of cellular death and survival pathways by conjugated bile acids. BMC Biochem. 2001, 2, 11, doi:10.1186/1471-2091-2-11.

16. Monte, M.J.; Marin, J.J.G.; Antelo, A.; Vazquez-Tato, J. Bile acids: Chemistry, physiology, and pathophysiology. World J. Gastroenterol. 2009, 15, 804-816.

17. KullakUblick, G.A.; Stieger, B.; Meier, P.J. Enterohepatic bile salt transporters in normal physiology and liver disease. Gastroenterology 2004, 126, 322-342.

18. Mukhopadhyay, S.; Maitra, U. Chemistry and biology of bile acids. Curr. Sci. 2004, 87, 1666-1683.

19. Merkus, F.W.H.M.; Schipper, N.G.M.; Verhoef, J.C. The influence of absorption enhancers on intranasal insulin absorption in normal and diabetic subjects. J. Control. Release 1996, 41, 69-75.

20. Kim, N.D.; Im, E.K.; Hyun Choi, Y.; Hyun Yoo, Y. Synthetic bile acids: Novel mediators of apoptosis. J. Biochem. Mol. Biol. 2002, 35, 134-141.

21. Dial, E.J.; Rooijakkers, S.H.M.; Darling, R.L.; Romero, J.J.; Lichtenberger, L.M. Role of phosphatidylcholine saturation in preventing bile salt toxicity to gastrointestinal epithelia and membranes. J. Gastroenterol. Hepatol. 2008, 23, 430-436.

22. Garidel, P.; Hildebrand, A.; Knauf, K.; Blume, A. Membranolytic activity of bile salts: Influence of biological membrane properties and composition. Molecules 2007, 12, 2292-2326.

23. Zughaid, H.; Forbes, B.; Martin, G.P.; Patel, N. Bile salt composition is secondary to bile salt concentration in determining hydrocortisone and progesterone solubility in intestinal mimetic fluids. Int. J. Pharm. 2012, 422, 295-301.

24. Wiedmann, T.S.; Kamel, L. Examination of the solubilization of drugs by bile salt micelles. J. Pharm. Sci. 2002, 91, 1743-1764.

25. Small, D.M.; Admirand, W. Solubility of bile salts. Nature 1969, 221, 265-267.

26. Russell, D.W. Fifty years of advances in bile acid synthesis and metabolism. J. Lipid Res. 2009, S120-S125, doi:10.1194/jlr.R800026-JLR200.

27. Hofmann, A.F.; Mysels, K.J. Bile salts as biological surfactants. Colloid Surf. 1987, 30, 145-173.

28. Ravichandran, G.; Gopinath, D. Ultrasonic relaxation studies on micelle formation in aqueous solutions of some bile salts. J. Mol. Liq. 2014, 198, 122-127.

29. Barrasa, J.I.; Olmo, N.; Lizarbe, M.A.; Turnay, J. Bile acids in the colon, from healthy to cytotoxic molecules. Toxicol. In Vitro 2013, 27, 964-977.

30. Claro da Silva, T.; Polli, J.E.; Swaan, P.W. The solute carrier family 10 (SLC10): Beyond bile acid transport. Mol. Asp. Med. 2013, 34, 252-269. 
31. Qi, Y.; Jiang, C.; Cheng, J.; Krausz, K.W.; Li, T.; Ferrell, J.M.; Gonzalez, F.J.; Chiang, J.Y.L. Bile acid signaling in lipid metabolism: Metabolomic and lipidomic analysis of lipid and bile acid markers linked to anti-obesity and anti-diabetes in mice. Biochim. Biophys. Acta 2015, 1851, 19-29.

32. Cremers, C.M.; Knoefler, D.; Vitvitsky, V.; Banerjee, R.; Jakob, U. Bile salts act as effective protein-unfolding agents and instigators of disulfide stress in vivo. Proc. Natl. Acad. Sci. USA 2014, 4, E1610-E1619.

33. Yin, S.; Zhai, Z.; Wang, G.; An, H.; Luo, Y.; Hao, Y. A novel vector for lactic acid bacteria that uses a bile salt hydrolase gene as apotential food-grade selection marker. J. Biotechnol. 2011, 152, 49-53.

34. Strauch, E.D.; Yamaguchi, J.; Bass, B.L.; Wang, J.Y. Bile salts regulate intestinal epithelial cell migration by nuclear factor- $K \beta$-induced expression of transforming growth factor- $\beta . \mathrm{J}$. Am. Coll. Surg. 2003, 197, 974-984.

35. Keating, N.; Keely, S.J. Bile acids in regulation of intestinal physiology. Curr. Gastroenterol. Rep. 2009, 11, 375-382.

36. Soroka, C.J.; Boyer, J.L. Biosynthesis and trafficking of the bile salt export pump, BSEP: Therapeutic implications of BSEP mutations. Mol. Asp. Med. 2014, 37, 3-14.

37. Kumar, D.P.; Rajagopal, S.; Mahavadi, S.; Mirshahi, F.; Grider, J.R.; Murthy, K.S.; Sanyal, A.J. Activation of transmembrane bile acid receptor TGR5 stimulates insulin secretion in pancreatic $\beta$ cells. Biochem. Biophys. Res. Commun. 2012, 427, 600-605.

38. Torcello-Gómez, A.; Foster, T.J. Interactions between cellulose ethers and a bile salt in the control of lipid digestion of lipid-based systems. Carbohydr. Polymers 2014, 113, 53-61.

39. Elnaggar, Y.S. Multifaceted applications of bile salts in pharmacy: An emphasis on nanomedicine. Int. J. Nanomed. 2015, 10, 3955-3971.

40. Goldberg, A.A.; Titorenko, V.I.; Beach, A.; Sanderson, J.T. Bile acids induce apoptosis selectively inandrogen-dependent and -independentprostate cancer cells. Peer J. 2013, 1, e122, doi:10.7717/peerj.122.

41. Hussain, A.; Arnold, J.J.; Khan, M.A.; Ahsan, F. Absorption enhancers in pulmonary protein delivery. J. Control. Release 2004, 94, 15-24.

42. Goto, T.; Holzinger, F.; Hagey, L.R.; Cerrè, C.; Ton-Nu, H.T.; Schteingart, C.D.; Steinbach, J.H.; Shneider, B.L.; Hofmann, A.F. Physicochemical and physiological properties of $5 \alpha$-cyprinol sulfate the toxic bile salt of cyprinid fish. J. Lipid Res. 2003, 44, 1643-1651.

43. Ananthapadmanabhan, K.P.; Goddard, E.D.; Turro, N.J.; Kuo, P.L. Fluorescence probes for critical micelle concentration. Langmuir 1985, 1, 352-355.

44. Charman, W.N.; Porter, C.J.H.; Mithani, S.; Dressman, J.B. Physicochemical and physiological mechanisms for the effects of food on drug absorption: The role of lipids and pH. J. Pharm. Sci. 1997, 86, 269-282.

45. Hofmann, A.F.; Rods, A. Physicochemical properties of bile acids and their relationship to biological properties: An overview of the problem. J. Lipid Res. 1984, 25, 1477-1489.

46. Mills, C.O.; Martin, G.H.; Elias, E. The effect of tyrosine conjugation on the critical micellar concentration of free and glycine-conjugated bile salts. Biochim. Biophys. Acta 1986, 876, $677-683$. 
47. Meaneya, C.M.; O’Driscoll, C.M. A comparison of the permeation enhancement potential of simple bile salt and mixed bile salt: Fatty acid micellar systems using the CaCo-2 cell culture model. Int. J. Pharm. 2000, 207, 21-30.

48. Senel, S.; Duchene, D.; Hincal, A.A.; Capan, Y.; Ponchel, G. In vitro studies on enhancing effect of sodium glycocholate on transbuccal permeation of morphine hydrochloride. J. Control. Release 1998, 51, 107-113.

49. Spivak, W.; Morrison, C.; Devinuto, D.; Yuey, W. Spectrophotometric determination of the critical micellar concentration of bile salts using bilirubin monoglucuronide as a micellar probe. Biochem. J. 1988, 252, 275-281.

50. Mahalingam, R.; Ravivarapu, H.; Redkar, S.; Li, X.; Jasti, B.R. Transbuccal delivery of 5-Aza-2'-deoxycytidine: Effects of drug concentration, buffer solution, and bile salts on permeation. AAPS Pharm. Sci. Technol. 2007, 8, E1-E6.

51. Dias, R.; Sakhare, S.; Mali. K. In vitro absorption studies of mucoadhesive tablets of Acyclovir. Indian J. Pharm. Educ. Res. 2010, 44, 183-188.

52. Salama, N.N.; Eddington, N.D.; Fasano, A. Tight junction modulation and its relationship to drug delivery. Adv. Drug Deliv. Rev. 2006, 58, 15-28.

53. Song, K.H.; Chung, S.J.; Shim, C.K. Enhanced intestinal absorption of salmon calcitonin (sCT) from proliposomes containing bile salts. J. Control. Release 2005, 106, 298-308.

54. Cetin1, M.; SinanAktas, M.; Vural, I.; Ozturk, M. Salmon calcitonin-loaded Eudragit ${ }^{\circledR}$ and Eudragit $^{\circledR}$-PLGAnanoparticles: In vitro and in vivo evaluation. J. Microencapsul. 2012, 29, $156-166$.

55. Moghimipour, E.; Jalali, A.; SajjadiTabassi, S.A.; Löbenberg, R. The enhancing effect of sodium glycocholate and sodium salicylate on rats gastro-intestinal permeability to insulin. Iran. J. Pharm. Res. 2004, 2, 87-91.

56. Jalali, A.; Moghimipour, E.; Akhgari, A. Enhancing effect of bile salts on gastrointestinal absorption of insulin. Trop. J. Pharm. Res. 2014, 13, 1797-1802.

57. Kavitha, K.; More, R.M.; Patel, D.M.; Sandeep, D.S.; Ganesh, N.S. Chemical permeation enhancers for transdermal drug delivery: A brief review. Der Pharm. Lett. 2010, 2, 358-365.

58. Shembale, A.I.; Borole, D.K.; Lohiya, R.T. Useful permeation enhancers for transdermal drug delivery: A review. Int. J. Pharm. Res. Dev. 2010, 2, 1-6.

59. Jain, H. Effect of penetration enhancer on in vitro release of diclofenac sodium gel formulation. Int. J. Pharm. Res. Dev. 2011, 2, 62-72.

60. Valenta, C.; Nowack, E.; Bernkop-Schnurch, A. Deoxycholate-hydrogels: Novel drug carrier systems for topical use. Int. J. Pharm. 1999, 185, 103-111.

61. Senyigit, T.; Tekmen, I.; Sönmez, Ü.; Santi, P.; Özer, Ö. Deoxycholate hydrogels of betamethasone-17-valerate intended for topical use: In vitro and in vivo evaluation. Int. J. Pharm. 2011, 403, 123-129.

62. Kouchak, M.; Handali, S. Effects of various penetration enhancers on penetration of aminophylline through shed snake skin. Jundishapur J. Nat. Pharm. Prod. 2014, 9, 24-29.

63. Moghimipour, E.; SajjadiTabassi, S.A.; Kouchak, M.; Varghaei, H. Combination strategies for enhancing transdermal absorption of theophylline through shed snake skin. Asian J. Pharm. Clin. Res. 2012, 5, 30-34. 
64. Benson, H.A. Transdermal drug delivery: Penetration enhancement techniques. Curr. Drug Deliv. 2005, 2, 23-33.

65. Hamman, J.H.; Stander, M.; Kotze, A.F. Effect of the degree of quaternisation of $N$-trimethyl chitosan chloride on absorption enhancement: In vivo evaluation in rat nasal epithelia. Int. J. Pharm. 2002, 232, 235-242.

66. Merkus, F.W.H.M.; Schipper, N.G.M.; Hermens, W.A.J.J.; Romeijn, S.G.; Verhoef, J.C. Absorption enhancers in nasal drug delivery: Efficacy and safety. J. Control. Release 1993, 24, 201-208.

67. Kushwaha, S.K.S.; Kumar Keshari, R.; Rai, A.K. Advances in nasal trans-mucosal drug delivery. J. Appl. Pharm. Sci. 2011, 1, 21-28.

68. Ozsoy, Y.; Gungor, S.; Cevher, E. Nasal delivery of high molecular weight drugs. Molecules 2009, 14, 3754-3779.

69. Pillion, D.J.; Amsden, J.A.; Kensil, C.R.; Recchia, J. Structure-function relationship among Quillaja saponins serving as excipients for nasal and ocular delivery of Insulin. J. Pharm. Sci. 1996, 85, 518-524.

70. Hirai, S.; Yashiki, T.; Mima, H. Mechanisms for the enhancement of the nasal absorption of insulin by surfactants. Int. J. Pharm. 1981, 9, 173-184.

71. Gordon, G.S.; Moses, A.C.; Silver, R.D.; Flier, J.S.; Carey, M.C. Nasal absorption of insulin: Enhancement by hydrophobic bile salts. Proc. Natl. Acad. Sci. USA 1985, 82, 7419-7423.

72. Türker. S.; Onur, E.; Özer, Y. Nasal route and drug delivery systems. Pharm. World Sci. 2004, 26, $137-142$.

73. Uchida, N.; Maitani, Y.; Machida, Y.; Nakagaki, M.; Nagai, T. Influence of bile salts on the permeability of insulin through the nasal mucosa of rabbits in comparison with dextran derivatives. Int. J. Pharm. 1991, 74, 95-103.

74. Bagger, M.A.; Wulff Nielsen, H.; Bechgaard, E. Nasal bioavailability of peptide T in rabbits: Absorption enhancement by sodium glycocholate and glycofurol. Eur. J. Pharm. Sci. 2001, 14, 69-74.

75. Bowe, C.L.; Mokhtarzadeh, L.; Venkatesan, P.; Babu, S.; Axelrod, H.R.; Sofia, M.J.; Kakarla, R.; Chan, T.Y.; Kim, J.S.; Lee, H.J.; et al. Design of compounds that increase the absorption of polar molecules. Proc. Natl. Acad. Sci. USA 1997, 94, 12218-12223.

76. Aungst, B.J.; Rogers, N.J.; Shefter, E. Comparison of nasal, rectal, buccal, sublingual and intramuscular insulin efficacy and the effects of a bile salt absorption promoter. J. Pharmacol. Exp. Ther. 1998, 244, 23-27.

77. Dondeti, P.; Zia, H.; Needham, T.E. In vivo evaluation of spray formulations of human insulin for nasal delivery. Int. J. Pharm. 1995, 122, 91-105.

78. Harai, S.; Ikenaga, T.; Matsuzawa, T. Nasal absorption ofinsulin in dogs. Diabetes 1978, 27, 296-299.

79. SajadiTabassi, S.A.; Hosseinzadeh, H.; Ramezani, M.; Moghimipour, E.; Mohajeri, S.A. Isolation, characterization and study of enhancing effects on nasal absorption of insulin in rat of the total saponin from Acanthophyllumsquarrosum. Indian J. Pharmacol. 2007, 39, 226-230.

80. Dodla, S.; Velmurugan, S. Buccal penetration enhancers-an review. Asian J. Pharm. Clin. Res. 2013, 6, 39-47. 
81. Hearnden, V.; Sankar, V.; Hull, K.; VidovićJuras, D.; Greenberg, M.; Ross Kerr, A.; Lockhart, P.B.; Patton, L.L.; Porter. S.; Thornhill, M.H. New developments and opportunities in oral mucosal drug delivery for local and systemic disease. Adv. Drug Deliv. Rev. 2012, 64, 16-28.

82. Oh, D.H.; Chun. K.H.; Jeon, S.O.; Kang, J.W.; Lee, S. Enhanced transbuccal salmon calcitonin (sCT) delivery: Effect of chemical enhancers and electrical assistance on in vitro sCTbuccal permeation. Eur J. Pharm. Biopharm. 2011, 79, 357-363.

83. Hoogstraate, A.J.; Senel, S.; Cullander, C.; Verhoef, J.; Junginger, H.E.; Bodd, H.E. Effects of bile salts on transport rates and routes of FITC-labelled compounds across porcine buccal epithelium in vitro. J. Control. Release 1996, 40, 211-221.

84. Bernstein, G. Delivery of insulin to the buccal mucosa utilizing the RapidMist ${ }^{\mathrm{TM}}$ system. Expert Opin. Drug Deliv. 2008, 5, 1047-1055.

85. Gandhi, R.; Robinson, J. Mechanisms of penetration enhancement for transbuccal delivery of salicylic acid. Int. J. Pharm.1992, 85, 129-140.

86. Ganem-Quintanara, A.; Kalia, Y.N.; Falson-Rieg, F.; Buri, P. Mechanisms of oral permeation enhancement. Int. J. Pharm. 1997, 156, 127-142.

87. Yamamoto, A.; Hayakawa, E.; Kato, Y.; Nishiura, A.; Lee, V.H. A mechanistic study on enhancement of rectal permeability to insulin in albino rabbits. J. Pharmacol. Exp. Ther. 1992, 263, 25-31.

88. Kim1, D.W.; Ramasamy, T.; Choi, J.Y.; Kim, J.H.; Yong, C.S.; Kim, J.O.; Choi, H.G. The influence of bile salt on the chemotherapeutic response of docetaxelloaded thermosensitive nanomicelles. Int. J. Nanomed. 2014, 9, 3815-3824.

89. Saettone, M.F.; Chetoni, P.; Cerbai, R.; Mazzanti, G.; Braghiroli, L. Evaluation of ocular permeation enhancers: In vitro effects on corneal transport of four $\beta$-blockers, and in vitro/in vivo toxic activity. Int. J. Pharm. 1996, 142, 103-113.

90. Yamamoto, A.; Luo, A.; Dodda-Kashi, S.; Lee, V. The ocular route for systemic insulin delivery in the albino rabbit. J. Pharmacol. Exp. Ther. 1989, 249, 249-255.

91. Nicolazzo, J.A.; Reed, B.L.; Finnin, B.C. Buccal penetration enhancers-How do they really work? J. Control. Release 2005, 105, 1-15.

92. Stojancevic, M.; Pavlovic, N.; Golocorbin-Kon, S.; Mikov, M. Application of bile acids in drug formulation and delivery. Front. Life Sci. 2013, 7, 112-122.

93. Wang, Y.; Zuo, Z.; Chow, M.S.S. HO-1-u-1 model for screening sublingual drug delivery-Influence of pH, osmolarity and permeation enhancer. Int. J. Pharm. 2009, 370, 68-74.

94. Shaikh, M.S.I.; Derle, N.D.; Bhamber, R. Permeability enhancement techniques for poorly permeable drugs: A review. J. Appl. Pharm. Sci. 2012, 2, 34-39.

95. Hinchcliffe, M.; Illum, L. Intranasal insulin delivery and therapy. Adv. Drug Deliv. Rev. 1999, 35, 199-234.

96. Lin, H.; Gebhardt, M.; Bian, S.; Kwon, K.A.; Shim, C.K.; Chung, S.J.; Kim, D.D. Enhancing effect of surfactants on fexofenadine. HCltransportacross the human nasal epithelial cell monolayer. Int. J. Pharm. 2007, 330, 23-31.

97. Lee, V.H.L.; Yamamoto, A. Penetration and enzymatic barriers to peptide and protein absorption. Adv. Drug Deliv. Rev. 1990, 4, 171-207. 
98. Alpar, H.O.; Eyles, J.E.; Williamson, E.D.; Somavarapu, S. Intranasal vaccination against plague, tetanus and diphtheria. Adv. Drug Deliv. Rev. 2001, 51, 173-201.

99. Naveen, C.; Kiran Kumar, Y.; Venkateshwar Rao, P.; Rama Rao, T. Chemical enhancers in buccal and sublingual delivery. Int. J. Pharm. Sci. Nanothecnol. 2011, 4, 1307-1319.

100. Yamamoto, A.; Hayakawa, E.; Lee, V.H.L. Insulin and proinsulin proteolysis in mucosal homogenates of the albino rabbit: Implications in peptide delivery from nonoral routes. Life Sci. 1990, 47, 2465-2474.

101. Nakada, Y.; Awata, C.; Nakamichi, C.; Sugimoto, I. The effectof additives on the oral mucosal absorption of humancalcitonin in rats. J. Pharmacobiol. Dyn. 1988, 11, 395-401.

102. Duchateau, G.S.M.J.E.; Zuidema, J.; Merkus, F.W.H.M. Bile salts and intranasal drug absorption. Int. J. Pharm. 1986, 31, 193-199.

103. Wheatley, M.A.; Dent, J.; Wheeldon, E.B.; Smith, P.L. Nasal drug delivery: An in vitro characterization of transepitehlial electrical properties and fluxes in the presence or absence of enhancers. J. Control. Release 1998, 8, 167-177.

104. Radwana, M.A.; Aboul-Enein, H.Y. The effect of absorption enhancers on the initialdegradation kinetics of insulin by $\alpha$-chymotrypsin. Int. J. Pharm. 2001, 217, 111-120.

105. Morimoto, K.; Uehara, Y.; Iwanaga, K.; Kakemi, M.; Ohashi, Y.; Tanaka, A.; Nakai, Y. Influence of absorption enhancers (bile salts) and the preservative (benzalkonium chloride) on mucociliary function and permeation barrier function in rabbit tracheas. Eur. J. Pharm. Sci. 1998, 6, 225-230.

106. Greenwood, J.; Adu, J.; Davey, A.J.; Abbott, N.J.; Bradbury, M.W.B. The effect of bile salts on the permeability and ultrastructure of the perfused, energy-depleted, rat blood-brain barrier. J. Cereb. Blood Flow Metab. 1991, 11, 644-654.

107. Barrios, J.M.; Lichtenberger, L.M. Role of biliary phosphatidylcholine in bile acid protection and NSAID injury of the ileal mucosa in rats. Gastroenterology 2000, 118, 1179-1186.

108. Tan, Y.; Qi, J.; Lu, Y.; Hu, F.; Yin, Z.; Wu, W. Lecithin in mixed micelles attenuates the cytotoxicity of bile salts in Caco-2 cells. Toxicol. in Vitro 2013, 27, 714-720.

109. Zhang, Y.; Jiang, X.G.; Yao, J. Nasal absorption enhancement of insulin by sodium deoxycholate in combination with cyclodextrins. Acta Pharmacol. Sin. 2001, 22, 1051-1056.

110. Muheem, A.; Shakeel, F.; Jahangir, M.A.; Anwara, M.; Mallick, N.; Kumar Jain, G.; Husain Warsia, M.; Jalees Ahmad, F. A review on the strategies for oral delivery of proteins and peptides and their clinical perspectives. Saudi Pharm. J. 2014, doi:10.1016/j.jsps.2014.06.004.

111. Kim, H.; Kim, Y.; Lee, J. Liposomal formulations for enhanced lymphatic drug delivery. Asian J. Pharm. Sci. 2013, 8, 96-103.

112. Niua, M.; Lu, Y.;Hovgaard, L.; Guan, P.; Tan, Y.; Lian, R.; Qi, J.; Wu, W. Hypoglycemic activity and oral bioavailability of insulin-loaded liposomes containing bile salts in rats: The effect of cholate type, particle size and administered dose. Eur. J. Pharm. Biopharm. 2012, 81, 265-272.

113. Mann, J.F.; Ferro, V.A.; Mullen, A.B.; Tetley, L.; Mullen, M.; Carter, K.C.; Alexander, J.; Stimson, W.H. Optimisation of a lipid based oral delivery system containing A/Panama influenza haemagglutinin. Vaccine 2004, 22, 2425-2429.

114. Guan, P.; Lu, Y.; Qi, J.;Niu, M.;Lian, R.; Hu, F.; Wu, W. Enhanced oral bioavailability of cyclosporine A by liposomes containing a bile salt. Int. J. Nanomed. 2011, 6, 965-974. 
115. Conacher, M.; Alexander, J.; Brewer, J.M. Oral immunisation with peptide and protein antigens by formulation in lipid vesicles incorporating bile salts (bilosomes). Vaccine 2001, 19, 2965-2974.

116. Mann, J.F.; Scales, H.E.; Shakir, E.; Alexander, J.; Carter, K.C.; Mullen, A.B.; Ferro, V.A. Oral delivery of tetanus toxoid using vesicles containing bile salts (bilosomes) induces significant systemic and mucosal immunity. Methods 2006, 38, 90-95.

117. Shukla, A.; Khatri, K.; Gupta, P.N.; Goyal, A.K.; Mehta, A.; Vyas, S.P. Oral immunization against hepatitis B using bile salt stabilized vesicles (bilosomes). J. Pharm. Pharm. Sci. 2008, 11, 58-66.

Sample Availability: Samples of the compounds are not available.

(C) 2015 by the authors; licensee MDPI, Basel, Switzerland. This article is an open access article distributed under the terms and conditions of the Creative Commons Attribution license (http://creativecommons.org/licenses/by/4.0/). 